\title{
Dynamic Financial Analysis in the Insurance Industry
}

\author{
Yung-Ming Shiu \\ Department of Business Administration, National Cheng Kung University, 1, University Road, Tainan, \\ Taiwan. \\ E-mail: yungming@mail.ncku.edu.tw
}

\begin{abstract}
Although dynamic financial analysis (DFA) has gradually gained attention over the recent years, knowledge is scant about the practices in the insurance industry. The objective of this paper is to provide insights into the practices. The investigation is conducted via a field study in five U.K. insurance companies. An example is given to illustrate how DFA works in general. The results highlight key matters that actuaries emphasise when carrying out dynamic financial analysis. This paper sets out important implications that insurance regulators and the actuarial profession can take into account as they refine their supervisory and regulatory regime.
\end{abstract}

The Geneva Papers (2009) 34, 175-196. doi:10.1057/gpp.2009.1

Keywords: dynamic financial analysis; financial condition reporting; insurance; interview

\section{Introduction}

By pooling risks of individual customers, the insurer, as a risk pooler and financial intermediary, can diversify away some of the specific risks faced by customers. During this decade, there has been substantial growth in the use of dynamic financial analysis (DFA) in the insurance industry. In order to assess an insurer's risk tolerance, solvency status and management strategies, actuaries use DFA to forecast its future condition under a set of adverse scenarios. Insurance regulators have gradually adopted riskbased approaches to regulating the insurance business. Insurers currently not using DFA will probably adopt something along the lines of DFA in the near future. Financial condition reports (FCRs) are the outputs of DFA models. It is worthwhile mentioning that DFA is sometimes used as the generic term for dynamic solvency testing (DST). In 2003, the US Dynamic Financial Analysis Committee of the Casualty Actuarial Society changed its name to the Dynamic Risk Modelling (DRM) Committee to reflect the fact that DFA is just one type of DRM. Nevertheless, because insurance market practitioners are relatively familiar with the term DFA rather than DRM, the term DFA will be used in this paper.

Several insurance regulatory authorities and actuarial professional bodies provide guidelines to help actuaries employ DFA techniques to evaluate an insurer's financial health. For instance, in 1996 the U.K. Life Board of the Faculty and Institute of Actuaries introduced Guidance Note 2 (GN2), which was subsequently revised to a small extent after the Financial Services and Markets Act 2000 took effect, as Recommended Practice for appointed actuaries responsible for the life insurance business. Although there is no GN2 counterpart in non-life insurance, DFA is still gaining its popularity in the non-life sector. Guidance Notes GN46 and GN47 were 
subsequently introduced in 2004. Both were prepared in order to help actuaries use DFA techniques to carry out capital assessment. However, knowledge is scant about how and what actuaries do in a DFA exercise and their opinions about related guidelines. This study is of an exploratory nature and provides insights into DFA and FCR practices. Specifically, the objective of this paper is to answer the following main questions: (1) how do actuaries conduct DFA and produce FCR? (2) what are their views on related regulations? and (3) what are the obstacles companies face in implementing DFA/FCR?

This paper seeks to contribute to the growing literature on DFA/FCR in several principal ways. The first contribution is to reveal the DFA/FCR practices through interviews. To date, no interview evidence exists that attempts to investigate the use of DFA techniques and FCR within insurance companies. Some studies ${ }^{1}$ have examined the extent of the use of DFA/FCR. These studies have one thing in common: all were carried out through a postal survey. Although such a survey may obtain responses from a large number of samples, in-depth field research, such as the present study, can produce much more detailed information. Moreover, the analysis of the results obtained from this study reveals some of the important components and their level of detail, which are included in relevant applications by practitioners. The industry practices reported in this study could be used as a reference for actuaries charged with the task of DFA modelling. Second, this study extends the existing literature by soliciting views from appointed/chief actuaries on related guidelines and future possible developments in DFA within companies. No study has ever addressed such issues. Third, this research provides insights into the DFA/FCR practices of U.K. insurance firms. By analysing the U.K. insurance sector, this study is able to control for the potentially confounding differences in regulations across countries. The results obtained can be compared with those from U.S.-based studies.

The rest of this paper is organised as follows. The next section locates this research within the literature on DFA and FCR. The subsequent section describes and justifies the research method and the section thereafter presents and analyses interview evidence. A DFA example is illustrated in the penultimate section. The final section concludes the paper.

\section{Review of prior research}

Very little research has been carried out to investigate the DFA and FCR practices in the insurance industry. In 1994, the DST Working Party of the Faculty and Institute of Actuaries mailed a questionnaire to appointed actuaries of U.K. life insurers to investigate the DST practices. The purpose of this survey was to reveal what the practices are so that suitable guidance on FCR might be drafted accordingly. As stated previously, the Life Board of the Faculty and Institute of Actuaries introduced GN2 in 1996. At the end of the same year, Muir and Sarjant ${ }^{2}$ posted a questionnaire to appointed actuaries of U.K. life firms and friendly societies to discover how the industry

\footnotetext{
${ }^{1}$ For example Dynamic Solvency Testing Working Party (1994); Muir and Sarjant (1997); Shiu et al. (2006); Shiu and Moles (2006).

${ }^{2}$ Muir and Sarjant (1997).
} 
complied with GN2. In order to find out whether the practices have changed, among other things, Shiu et al. ${ }^{3}$ and Shiu and Moles $^{4}$ simultaneously administered two postal surveys for U.K. life and non-life firms, respectively, in 2002. Their work serves as an update and the findings can be compared with those of previous studies. In sum, the previous studies generally examine the technical issues on DFA and FCR. In contrast, this fieldwork addresses the related issues but from a non-technical perspective. We attempt to solicit the thinking behind actuaries' use of DFA techniques and FCR.

It is noteworthy that the Integrated Prudential Sourcebook of the Financial Services Authority came into force for all U.K. authorised insurers at the end of 2004. GN46 and GN47 issued by the Life Board of the Faculty and Institute of Actuaries were brought into effect from 31 December 2004, while GN2 now appears obsolete. GN46 provides guidance on life insurance Individual Capital Assessment and GN47 on stochastic modelling for reserving and capital assessment. The techniques mentioned in these two guidance notes include scenario testing, stress testing and stochastic modelling, all of which are DFA techniques.

\section{Method}

Although postal surveys have several merits including large sample size and low cost, at the same time they have weaknesses such as relative unreliability of data in terms of accuracy and typically low response rate. ${ }^{5}$ Moreover, in order to attempt to achieve a high response rate, the questionnaire generally is designed to be short and the questions generally are closed-ended. Thus, some of the questions unavoidably would not go into too much detail or some minor questions were not even asked because of the limited length of the questionnaire. Given the drawbacks of the questionnaire, it was determined that semistructured interviews allowing interviewees to express themselves according to their own systems of meanings ${ }^{6}$ would serve this purpose at the exploratory stage of this research.

\section{The interview selection, instrument and process}

Five U.K. insurers were interviewed. Additional selection criteria were applied to ensure that a range of industry sectors, geographical locations, firm size, product mix and use of DFA/FCR were represented in the sample. ${ }^{7}$ Three of them are life insurers with DFA and FCR in place. Two of them are non-life insurers. One of the two has DFA and FCR, but the other only has DFA. Company locations included London and Scotland. Written premiums ranged from $£ 5$ million to £4billion. Insurance products sold included all common life contracts (e.g. non-linked contracts, accumulating with-profit policies and property-linked contracts) and non-life policies (e.g. accident and health, liability and motor insurance).

\footnotetext{
${ }^{3}$ Shiu et al. (2006).

${ }^{4}$ Shiu and Moles (2006).

${ }^{5}$ Gillham (2000).

${ }^{6}$ Rubin and Rubin (1995).

${ }^{7}$ Eisenhardt (1989).
} 
A copy of topics for discussion was sent with a cover letter to each of the prospective interviewees. Their titles mainly are appointed/chief/pricing actuaries or actuarial manager. The aim of posting the copy of topics for discussion was to ensure that the prospective interviewees understood the topics that would be discussed at the interview and had time to prepare before the interview if they were willing to do so. About 10 days after the letters were mailed, the prospective interviewees were contacted by telephone to arrange a mutually convenient time for a meeting. These interviews were conducted on the company premises and carried out by the same researcher who is an experienced DFA modeller. The length of the interviews varied between 60 and 90 minutes.

The interviews were semi-structured. Questions are designed to be open-ended and broad in order to bring to the surface actuaries' strategic thinking about the issues in question. While allowing flexibility for exploring emerging paths during the interview, the interview instrument specified certain themes identified from prior studies. These themes were grouped under three main headings entitled: "the risk profile of your company", "the use of DFA techniques in your company" and "FCR in your company". The instrument is available from the author upon request. These themes were developed based on the research aim and literature review.

A number of steps were taken with caution to increase the reliability and credibility of this filed study. First, three versions of topics for discussion were developed because of the type of insurer and its status of DFA/FCR use. The instrument was customised for each category of interviewees. Second, the purpose of the research and its progress to date were briefly presented to the interviewee before the interview. Third, the interviewee was assured that all the information provided would be treated in the strictest confidence and complete anonymity would be provided to their respective organisation. A relationship of trust was then built between the interviewer and interviewee by the confidentiality assurance and the common professional ground. Fourth, the interviewee was asked for permission to tape the interview in addition to note taking. The permission was sought for two reasons: (1) tape recording makes accurate and unbiased record possible, and (2) this record may serve as future reference and can be listened to again where necessary. Finally, the interviews were transcribed soon after the interviews in order to grasp the important points provided by the interviewees when the memory was still fresh. Follow-ups were made through phone calls and emails to clarify the interview transcripts. Judgement had to be, inevitably, exercised to determine what needs to be included in the transcripts. The exercise of judgement was based on the relevance of the material from the interviewee. Those that were not related to the topics and were not instrumental in understanding the practices of DFA/FCR, were excluded from the transcripts.

\section{The analysis of interview data}

Interview transcripts were content analysed using grounded theorising ${ }^{8}$ and a conceptual matrix for each organisation was developed to summarise the key points from the interviewees. These points were then assigned under a number of headings.

\footnotetext{
${ }^{8}$ Strauss and Corbin (1990).
} 
Most of the topics and themes were pre-specified. However, new topics or themes were set for some identified key points as long as they were relevant to the current practices in question. Finally, all these identified points, which had been assigned under the same heading of topics, were compared and contrasted in order to examine the similarities and differences among the organisations interviewed.

\section{Results}

\section{Profiles of interview participants}

While not compromising the confidentiality agreement reached, the profiles of the organisations interviewed are presented in Table 1. These corporations are referred to as Insurers A, B, C, D and E. Their use of DFA/FCR is also summarised in this table.

In order to set the stage for the analysis of interview evidence, a brief synopsis of each interview is reproduced below. The complete transcripts are available from the author upon request.

Insurer $\mathrm{A}$ is a life firm that uses DFA and produces an FCR. This firm sells traditional non-profit contracts, accumulating with-profit policies and property linked contracts. The main risks that the company faces are investment and mortality risks. Investment risk is the key one because most of the company's contracts are investment related. The ways of identifying the main risks, such as investment risk, are obvious to the company, but they have difficulty in quantifying operational risk and business risk. Thus, the DFA that the company uses is only focused on the changes in the investment market. Both sensitivity testing and scenario testing are used, whereas stochastic simulation is only applied to certain business lines. The projections are mainly deterministic and the forecast period is 5 years. The decision about which risk factors should be tested is mainly based on professional/actuarial judgement. The results of DFA investigations are deemed important and have led the company to take material measures in both underwriting and investment operations. Technology and data are regarded as the two biggest factors limiting the ability to use DFA techniques. The company plans to improve the application of stochastic modelling in the near future.

Insurer B is a life insurer with DFA and FCR in place. The main risks faced by this company are interest rate risk and mortality risk. The company relies largely on its appointed actuary's professional judgement to identify risks. Sensitivity testing is the main technique employed by the firm. The use of scenario testing is very limited. Stochastic simulation has never been used, but will be developed in the near future. No interactions are allowed between assets and liabilities. The DFA results have never affected company decisions about underwriting and investment operations. The difficulty in writing models and the cost of doing so are the main practical difficulties. An FCR is regarded as a worthwhile exercise and stochastic work will be included in FCR in the near future.

Insurer $\mathrm{C}$ is a life firm that uses both DFA and FCR. This firm sells unit-linked contracts and major annuity products. The main risks are expense, lapse and mortality risk. The company investigates its risk profile by doing relevant analyses regarding these main risks. Only very limited sensitivity testing is carried out due to a lack of resources. The decision about which risk factors should be tested is largely based on 
Table 1 The profiles of the organisations interviewed and their use of DFA/FCR

\begin{tabular}{|c|c|c|c|c|c|}
\hline & Insurer $A$ & Insurer $B$ & Insurer $C$ & Insurer $D$ & Insurer $E$ \\
\hline Type & Life & Life & Life & Non-life & Non-life \\
\hline DFA $^{\mathrm{a}}$ & $\sqrt{ }$ & $\sqrt{ }$ & $\sqrt{ }$ & $\sqrt{ }$ & $\sqrt{ }$ \\
\hline $\mathrm{FCR}^{\mathrm{b}}$ & $\sqrt{ }$ & $\sqrt{ }$ & $\sqrt{ }$ & $\sqrt{ }$ & $\times$ \\
\hline Title of interviewee & $\begin{array}{l}\text { Statutory } \\
\text { reporting and } \\
\text { pricing manager }\end{array}$ & $\begin{array}{l}\text { Appointed } \\
\text { actuary }\end{array}$ & $\begin{array}{l}\text { Actuarial } \\
\text { manager }\end{array}$ & $\begin{array}{l}\text { Pricing } \\
\text { actuary }\end{array}$ & Chief actuary \\
\hline \multirow[t]{4}{*}{ Types of insurance products ${ }^{\mathrm{c}}$} & NL & $\mathrm{UL}$ & NL & $\mathrm{AH}$ & $\mathrm{L}$ \\
\hline & AWP & & PL & MAT & MP \\
\hline & PL & & & & \\
\hline & & & & MP & \\
\hline \multirow[t]{3}{*}{ DFA technique ${ }^{\mathrm{d}}$} & SenT & SenT & \multirow[t]{3}{*}{ SenT } & SceT & SenT \\
\hline & SceT & SceT & & SS & SceT \\
\hline & SS & & & & SS \\
\hline Number of applications ${ }^{\mathrm{e}}$ & 6 & 1 & 2 & 2 & 3 \\
\hline Number of scenarios & $1-10$ & $1-10$ & $\mathrm{~N} / \mathrm{A}$ & $1-10$ & $1-10$ \\
\hline Frequency of scenario testing & Annually & Annually & $\mathrm{N} / \mathrm{A}$ & Quarterly & Half yearly \\
\hline Number of risk factors in scenarios ${ }^{\mathrm{f}}$ & 10 & 7 & $\mathrm{~N} / \mathrm{A}$ & 4 & 9 \\
\hline Economic variable modelling $\mathrm{g}$ & 2 & 0 & 2 & 0 & 5 \\
\hline Asset modelling ${ }^{\mathrm{h}}$ & I & I & I & I, II, III & I, II, IV \\
\hline Liability modelling ${ }^{\mathrm{i}}$ & I & II & I & $\mathrm{V}$ & I \\
\hline Forecast period & 5 years & 5 years & 5 years & 3 years & $>20$ years \\
\hline FCR available to a third party? & Yes & Yes & Yes & Yes & $\mathrm{N} / \mathrm{A}$ \\
\hline
\end{tabular}

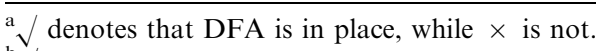

b $\sqrt{ }$ denotes that FCR is in place, while $\times$ is not.

${ }^{\mathrm{c}} \mathrm{NL}$ : non-linked contract (other than with-profit policy); AWP: accumulating with-profit policy; PL: property-linked contract; UL: unit-linked contract; IL: index-linked contract; AH: accident and health insurance; MAT: marine, aviation and transport insurance; L: liability insurance; M: motor insurance; P: property insurance; MP: miscellaneous and pecuniary loss insurance.

${ }^{\mathrm{d}}$ SenT: sensitivity testing; SceT: scenario testing; SS: stochastic simulation.

${ }^{\text {e}}$ Possible applications of the DFA techniques include solvency testing, capital allocation, evaluation of reinsurance programmes, development of business plans, pricing, asset allocation, surplus allocation, evaluation of mergers and acquisitions, and communicating the results to rating agencies.

${ }^{\mathrm{f}}$ The risk factors that are frequently included in scenarios include future investment conditions, level of new business, expenses, taxation, effects of asset-defaults, risk of reinsurer default, frequency and severity, pricing, mis-estimation of policy liabilities, deterioration of asset values, government and political action, and bonus rate, etc.

${ }^{\mathrm{g}}$ Economic variables include term structure of interests, inflation, equity returns, currency rates and credit spreads.

${ }^{\mathrm{h}} \mathrm{I}$ : can project the total investment return; II: assumptions can be varied from year to year; III: can vary income and gains independently; IV: separate model points for different asset classes; V: individual assets can be modelled.

${ }^{\mathrm{i}}$ I: all in-force policies; II: most in-force policies; III: a sample of in-force policies; IV: model points;

$\mathrm{V}$ : a sample of in-force policies individually.

${ }^{\mathrm{j}}$ Third parties include, for instance, (1) auditors of the firm and (2) the Financial Services Authority. 
actuarial judgement. The firm does not have a unified model to allow for interactions between assets and liabilities. The DFA results have never directly affected company decision. People and information technology are the two most significant factors limiting the capability for using DFA techniques. The company intends to do more work on stochastic modelling in the near future.

Insurer D is a non-life insurer that uses DFA and produces an FCR. This insurer writes all major lines of business, including accident and health, marine, aviation and transport, liability, motor, property, and miscellaneous and pecuniary loss. The main risks include premium risk, reserving risk, credit risk, etc. A proprietary system is used to manage aggregate risk exposure and is able to indicate the risk profile of each risk. The company has a mini-DFA model for pricing only and hopes to have an overall model combining assets and liabilities to evaluate the effects of different company strategies on solvency. In the mini-DFA model two variables, claim severity and frequency, are varied. The Wilkie investment model is not used because the company's business is generally short term. On many occasions the results of DFA investigations have led the company to take decisions about whether to write contracts on certain terms. It is company culture that limits the use of DFA techniques. An FCR is regarded as a worthwhile exercise and a Guidance Note on FCR, specifically for nonlife companies, is considered necessary.

Insurer $\mathrm{E}$ is a non-life insurer that uses DFA but does not produce an FCR. This company covers all types of non-life business. The main risks the company faces are centred around its liabilities. The biggest uncertainty is asbestos liability. The company tends to rely on in-house knowledge and expertise more than anything else in terms of understanding its risks. All DFA-related techniques are used. In this company, establishing which risk factors should be tested is quite judgemental. Pricing inflation is used as the key driving factor and the Wilkie investment model is used as part of the main model because the company is interested in the long-term results of projections. DFA is used to evaluate investment strategies. The DFA results have never led to any changes in underwriting operations. The parameterisation of the DFA model is regarded as the biggest factor, which limits the use of DFA. Most of the parameters are selected subjectively. These parameters will be updated continuously to reflect the latest market conditions. The company does not produce an FCR due to the nature of the company, but it will do so if it is required by the regulator. A Guidance Note is deemed necessary, if an FCR is made mandatory.

\section{Interview outcomes}

The interview outcomes are presented grouped by three key themes that are entitled "the risk profile", "DFA techniques" and "FCR".

\section{Risk profile}

The risk profile of a company depends on the business written. In life insurance, the main business has shifted from traditional mortality business of risk protection towards investment-related business. Thus, investment risk is the most common main 
risk faced by life insurers, particularly by with-profit life firms. Mortality risk presents a fairly significant degree of risk for the life firms, which transact pension and annuity business. For unit-linked firms, expense and lapse risks are two common risks. In nonlife business, it appears that the liability side of the balance sheet is the main concern of actuaries, especially for the companies writing long-term liability business. One nonlife insurer transacting long-tail liability business indicated that asbestos claims continue to be the greatest single threat to the stability of the company. If the reserves of the company are inadequate, the reserving risk could lead the company to insolvency. For instance, the insolvency of Sovereign Marine \& General Insurance Company resulted from the fact that its underwriting results worsened during the period 1988-1990 due to a steady rise in product-related hazard claims such as asbestos, pollution and workers' compensation claims. ${ }^{9}$

When asked how to identify material risks affecting company performance or how to establish which risk factors should be tested, most interview participants confirmed that it was mainly based on professional/actuarial judgement without conducting any analysis for the identification of the risk factors. Actuaries argue that there is no universally recognised method that can be employed to fully identify risks. Nevertheless, professional judgement is not always completely reliable. Only one interviewee stated that some analyses such as expense, mortality and lapse analyses were carried out in order to investigate the risk profile of the company. As Macdonald ${ }^{10}$ points out, financial economics or econometric analysis cannot replace actuarial judgement and it has its hands tied behind its back if it cannot call upon these concepts for guidance. It is deemed useful to conduct a statistical or econometric analysis in which actuarial judgement is still indispensable, to help actuaries correctly identify the factors which affect company performance and that should be considered being included in DFA modelling.

\section{DFA techniques}

The importance of conducting DFA was confirmed by all insurers. One of them only carried out sensitivity testing, while the remainder employed two or three techniques within their companies. This suggests that between organisations the use of DFA-related techniques varied.

It seems that the insurers reporting conducting stochastic modelling only used it in a very limited way. This was confirmed by one interviewee saying that "we only apply stochastic simulation to certain business lines". He further indicated that "this is probably a fairly common position at the moment. I cannot imagine that any company is able to apply stochastic techniques to its complete in-force book of business". The use of stochastic modelling was not commonly seen in the insurance industry, possibly because this approach involves costly investments in intellectual development and systems infrastructure. It requires substantially more computing power than scenario testing. Also, carrying out simulations can be a very time-consuming job. Moreover,

\footnotetext{
${ }^{9}$ KPMG (1999).

${ }^{10}$ Macdonald (1997).
} 
since the simulation method is prone to model risk, skilled analysts who have a good understanding of the relationships among underlying risk factors are required for this job. Furthermore, there are other common problems with stochastic modelling. For example, the parameters of Wilkie's model are not stable over time and there is a significant cross-correlation between the out-of-sample residuals. ${ }^{11}$

When asked specifically about the extent of allowing for interactions between assets and liabilities, those who mainly transact unit-linked contracts confirmed that "we can allow to the extent we have to, but that is very limited" or that "we do not have a unified model and it (the interaction) is not very important". Moreover, one non-life company that conducted stochastic modelling for pricing contracts confirmed that "we do actually model our assets vs. liabilities to come up with any investment strategies but we do not have a model which combines both assets and liabilities together". It seems that in practice the linkage between assets and liabilities is very limited. This is one of the drawbacks of traditional asset-liability models. ${ }^{12}$ It is a common perception that the results of DFA investigations are deemed more important for with-profit firms than for their unit-linked counterparts due to the nature of the business. This was confirmed by the interview participants. When asked about whether the results of DFA investigations ever led to the company taking any material measure in underwriting and investment operations, one interview participant from a withprofit firm confirmed that "along with other major with-profit firms, the results of solvency projections are very important". These DFA results usually affected company decisions about both underwriting and investment operations. In contrast, non-profit firms (e.g. unit-linked firms) all gave relatively negative responses to the same issue.

When asked about whether the results of DFA investigations ever led to the company taking any material measures in underwriting and investment operations, the two non-life interview participants gave different responses. One stated that DFA results affect underwriting decisions, whereas the other one said it affects investment decisions. This is probably because one of these two companies only used DFA to evaluate underwriting strategies, whereas the other firm only used DFA to evaluate investment strategies.

A range of responses was obtained when interview participants were asked what factors limited the ability to use DFA techniques. This reflects the diverse nature of the organisations represented. The responses also reflect that resources were different within individual organisations. The responses included "technology and data", "people and IT", "writing models and cost", "parameterization of the model" and "company culture". Lack of resources was a general response that could cover all the responses above, except the last one, which will be discussed next in more detail.

Although non-life insurance is a highly technical business, the actuarial involvement in the non-life insurance industry is not as much as that in the life insurance industry. According to "The Actuarial Directory 2002", 38 per cent and 33 per cent of U.K.

\footnotetext{
${ }^{11}$ Huber (1995).

12 Christofides (2000).
} 
fellows work in the pensions and life insurance industries, respectively, whereas only 8 per cent work in the non-life insurance industry. Many non-life insurance firms do not have actuaries probably because there are no statutory requirements and only relatively large non-life insurance companies have actuarial departments. In general, underwriters rely on their experience to underwrite policies. This was confirmed by one interviewee from a non-life insurance company who suggested that "our department (actuarial department) has been in place for only one year", going on to say that "it is the culture of the organisation that we try to change. Try to show that we can work with the underwriters to improve the understanding of the risks". It is worth noting that in practice underwriters sometimes exercise too much subjective judgement in underwriting. Using subjective judgement is not undesirable in itself, as long as it can help predict expected claims cost and other expenses.

When asked about what features of the DFA techniques the company plans to improve in the near future, all organisations expressed a desire to work on stochastic modelling. This belief may have been influenced by the FSA's policy of encouraging insurance companies to conduct stochastic modelling and by increased business imperatives requiring more understanding of company financial strength and the effects of chosen strategies on company performance, which can make stochastic modelling an attractive option. Overall, there seemed to be a general view that stochastic modelling was very much a tool that would be increasingly utilised in the insurance industry.

\section{FCR}

All the life firms interviewed prepared FCRs. However, due to the nature of individual business the FCRs produced by these firms are different in terms of content. In general with-profit firms have more complicated FCRs than non-profit firms. The following are usually included in the FCR: main risks, solvency projections, results of sensitivity testing and scenario testing, commentaries on new business strategies, business volume and investment market etc. When asked about the reasons for not producing FCRs, one non-life insurer who did not produce an FCR stated that "we have other reports covering similar things".

Two suggestions about improvements to Guidance Notes are made by the interviewees. First, more guidance on stochastic modelling should be included. Since the FSA has recently been encouraging insurance companies to do stochastic modelling for the purpose of monitoring solvency, more and more insurers are developing their capability for carrying out stochastic work. Therefore, it may be helpful to provide more relevant guidance for actuaries who are not familiar with stochastic modelling. Second, it would be desirable if Guidance Notes on FCRs specifically for non-life insurers could be drafted. When asked about whether it is necessary to introduce a Guidance Note on FCR specifically for non-life insurers, both non-life interviewees agreed that a relevant Guidance Note should be introduced, especially if it is mandatory to produce an FCR. In addition, all interviewees confirmed that an FCR is a worthwhile exercise and the FCR will be improved in some way in the coming years. 


\section{An illustrated DFA example}

The objective of this section is to illustrate an example to show how a DFA model works in general. It was decided to apply DynaMo 3 to solvency testing and asset allocation in non-life business. DynaMo 3 is a public access Excel-based model developed by the actuarial consulting firm Miller, Herbers, Lehmann \& Associates, Inc. ${ }^{13}$ This model consists of five primary modules, including the interest rate generator module, the investment module, the underwriting module, the reinsurance module and the catastrophe generator module. The rationale of including these modules in the model is as follows. First, both investment and underwriting operations are a non-life insurer's operations. Second, non-life companies generally focus more on the underwriting side. The risk exposure to catastrophe is one of their main concerns. They usually rely heavily on reinsurers due to the risky nature of their business. The other features of this model can be found in D'Arcy et al. ${ }^{14}$ and Walling et al. ${ }^{15}$

\section{The change made to DynaMo 3 and key modelling assumptions}

It is worth noting that the default parameters that are included in DynaMo 3 are mainly chosen to be illustrative. The actuaries of individual firms should select their own parameters to reflect the actual situations in their companies. For instance, historical data are used to calibrate the parameters required in the interest rate generator of DynaMo. ${ }^{16}$ According to D'Arcy et al. ${ }^{17}$ the data are from an actual U.S. non-life insurer. The initial set of inputs of DynaMo remains unchanged except where otherwise stated.

For simplicity, the invested asset mix comprises two categories of investments: equities and bonds. Specifically, the company only invests in ordinary shares and longterm government bonds with a maturity of more than 20 years. It is assumed that the hypothetical company invests $\$ 96,650$ thousand in these two assets (bond investment: $\$ 64,433$ thousand; equity investment: $\$ 32,217$ thousand). The starting point in time of the DFA exercise is at the end of 2007 and the model is used to project 5 years into the future. The company's balance sheet as of 31 December 2007 is shown in Table 2.

Expected surplus, also known as shareholders' funds or solvency margin, is chosen as the performance (return) measure in this analysis. Within an insurance context surplus not only represents the level of shareholders' wealth but also provides a cushion for absorbing unexpected losses. In the non-life business, the level of surplus is of particular importance because the permissible level of premiums written is generally expressed as a multiple of surplus such as the NAIC Property/Casualty IRIS Ratio 1

\footnotetext{
${ }^{13}$ DynaMo 3 is available to be downloaded from the Pinnacle website: http://www.pinnacleactuarialresources.com

${ }^{14}$ D'Arcy et al. (1997, 1998).

15 Walling et al. (1999).

${ }^{16}$ The reader may refer to Chan et al. (1992) and Nowman (1997) for approaches to calibrating models.

17 D'Arcy et al. (1998)
} 
Table 2 The balance sheet of the hypothetical company as of 31 December 2007 (\$000)

\begin{tabular}{lcrr}
\hline Assets & \multicolumn{2}{c}{ Liabilities } \\
\hline Invested assets: & & Technical reserves: & 34,402 \\
$\quad$ Long-term government bonds & 64,433 & Outstanding claims & 25,500 \\
$\quad$ Ordinary shares & 32,217 & Unearned premium & 2,598 \\
Other assets: & & Other liabilities & 40,000 \\
$\quad$ Agents balances & 5,200 & Surplus & 102,500 \\
$\quad$ Reinsurance recoverables & 650 & Total & \\
Total & 102,500 & & \\
\hline
\end{tabular}

(gross premiums written to policyholders' surplus) and Ratio 2 (net premiums written to policyholders' surplus).

Two risk measures are used in this analysis. The first is the standard deviation of surplus. This indicator measures the dispersion of the outcomes, but does not evaluate the severity. ${ }^{18}$ The second risk measure is the probability that the surplus will fall below the beginning statutory surplus over the next 5 years. The primary difference between the two is that the former focuses on the dispersion of the outcomes, whereas the latter focuses on the probability and severity of adverse outcomes.

Some of the other key assumptions used in the model include the following:

- Starting point: year-end 2007.

- Forecast period: 5 years (2008-2012).

- Only two lines of business: homeowners' multiple peril (HMP) and workers' compensation (WC).

- Trade-off ratio $=$ (percentage change in return measure $) /($ percentage change in risk measure).

- Parameters for the interest rate model: $\mathrm{a}=0.25, \mathrm{~m}=6$ per cent, $\sigma=5$ per cent, $\mathrm{r}_{2007}=4.91$ per cent.

- Parameters for the inflation rate model: $\mathrm{a}=0.015, \mathrm{~b}=0.75, \mathrm{~s}=0.7$ per cent.

- No impact of inflation on the number and severity of claims for HMP, and on the number of claims for WC. That is, inflation only has an impact on the severity of claims for WC.

- Market risk premium: 8.5 per cent.

- New business, first renewal business, and second and subsequent renewal business are modelled separately in order to reflect the ageing phenomenon. The frequencies of claims are assumed to be different, new business being the highest, and second and subsequent renewal business being the lowest.

- The company underwrites business equally in two places, where the frequency and severity of claims follow Poisson and Lognormal distributions, respectively. Place A: frequency Poisson (0.6667), severity Lognormal (12.76965, 1.516347); Place B: frequency $\sim$ Poisson (1.0556), severity $\sim$ Lognormal (11.28113, 0.584328).

\footnotetext{
${ }^{18}$ Lowe and Stanard (1996).
} 
- Non-catastrophe losses are projected using the loss development method, which is based on the assumption that claims move from unreported to reported-and-unpaid to paid in a pattern that is sufficiently consistent so that past experience can be used to predict future development.

- Written premiums in 2007: HMP (\$58 million) and WC (\$21.8 million).

- Expenses: HMP (32 per cent) and WC (27 per cent) of written premium.

- Two reinsurance programmes: Stop loss reinsurance (cost: 1 per cent of premium; maximum loss and allocated loss adjustment expense ratio: 76 per cent; maximum ceded amount: $\$ 5$ million) and catastrophe reinsurance (retention: $\$ 3$ million; size: \$25 million; cost: 2 per cent of premium).

- Underwriting cycles: phase $1=$ mature hard, phase $2=$ immature soft, phase $3=$ mature soft, phase $4=$ immature hard. The transition probabilities between underwriting cycle phases are shown in Table 3.

Both fixed and dynamic asset allocation strategies are considered in this paper. It should be noted that these strategies are only concerned with the invested assets, that is, equities and bonds and do not apply to other assets including agent balances and reinsurance recoverables. The fixed strategies used in the paper are similar to those of Macdonald, ${ }^{19}$ and Bohra and Weist. ${ }^{20}$ Table 4 defines the five fixed strategies, ranging from 100 to 0 per cent in equities and the remaining in bonds.

The fixed asset allocation strategies were denoted FAAS 1 (100 per cent in equities) to FAAS 5 (0 per cent in equities), whereas the corresponding dynamic asset allocation strategies DAAS 1 (100 per cent in equities) to DAAS 5 ( 0 per cent in equities). The dynamic asset allocation strategies used are variants of those of Macdonald ${ }^{21}$ and Hardy. ${ }^{22}$ Take DAAS 1 as an example. As stated in Table 5, the A/L ratio at the commencement of modelling is 1.64. From the first year to be modelled, the company, by default, invests 100 per cent of its funds in equities. However, if the A/L ratio falls below 1.54, the company progressively switches out of equities and into bonds, with 100 per cent bond investment if the $\mathrm{A} / \mathrm{L}$ ratio falls below 1.44 . As long as the $\mathrm{A} / \mathrm{L}$ ratio is greater than 1.54 , the company will return to 100 per cent equity investment. It should be noted that even if the A/L ratio falls below 1.54, DAAS 5 is the same as FAAS 5 because all the invested assets are bonds.

There are two main reasons behind this dynamic asset-switching algorithm. First, although equity returns are usually higher than bond returns, the risk associated with the former is also higher than that associated with the latter. A high proportion of equity investments may increase the risk of insolvency. The company has to strike a balance between solvency and high returns. It seems advisable not to take on extra risk and to be relatively conservative when the $\mathrm{A} / \mathrm{L}$ ratio is low. Second, most importantly, the valuation of equities does not allow for possible capital gain, but allows for

\footnotetext{
${ }^{19}$ Macdonald (1995).

${ }^{20}$ Bohra and Weist (2001).

${ }^{21}$ Macdonald (1995).

${ }^{22}$ Hardy (1996).
} 
The Geneva Papers on Risk and Insurance - Issues and Practice

188

Table 3 Transition probabilities between underwriting cycle phases

\begin{tabular}{lrrrr}
\hline Phase & \multicolumn{4}{c}{ Transition probability (\%) } \\
\cline { 2 - 5 } & 1 & 2 & 3 & 4 \\
\hline 1 & 50 & 40 & 5 & 5 \\
2 & 5 & 50 & 40 & 5 \\
3 & 5 & 5 & 50 & 40 \\
4 & 40 & 5 & 5 & 50
\end{tabular}

Table 4 Fixed asset allocation strategy

Strategy Percentage of invested assets invested in equities (\%)

Fixed asset allocation strategy 1 (FAAS 1)

Fixed asset allocation strategy 2 (FAAS 2)

Fixed asset allocation strategy 3 (FAAS 3)

100

Fixed asset allocation strategy 4 (FAAS 4)

Fixed asset allocation strategy 5 (FAAS 5)

Note: Invested assets include bond and equity investments.

Table 5 Number of insolvencies out of simulation 1,000 times

\begin{tabular}{lclc}
\hline Strategy & Number of insolvencies & Strategy & Number of insolvency \\
\hline FAAS 1 & 5 & DAAS 1 & 5 \\
FAAS 2 & 3 & DAAS 2 & 3 \\
FAAS 3 & 4 & DAAS 3 & 4 \\
FAAS 4 & 4 & DAAS 4 & 4 \\
FAAS 5 & 5 & DAAS 5 & 5 \\
\hline
\end{tabular}

dividend yield, which is usually lower than bond yield. Therefore, in order to demonstrate solvency a company usually switches out of equities and into bonds.

\section{Model output}

This subsection summarises the results, which are intentionally presented in terms that are familiar to actuaries and managers of non-life insurers. Simulation is performed 1,000 times. In order to reproduce the results and make them comparable, the starting random seed value has to be set at a fixed and randomly selected number. A number of 44 is chosen from a random number table to serve this purpose.

Table 5 shows the numbers of insolvencies $(\mathrm{A} / \mathrm{L}<1)$ out of 1,000 simulations for each of the 10 strategies defined above. The numbers of insolvencies are all relatively small. This is probably because the company whose $\mathrm{A} / \mathrm{L}$ at the commencement of modelling is 1.64 is financially strong. In addition, it seems that in the particular case in question, changes in the proportion of equity investments make relatively little difference in the number of insolvencies. There is a very small probability that the 

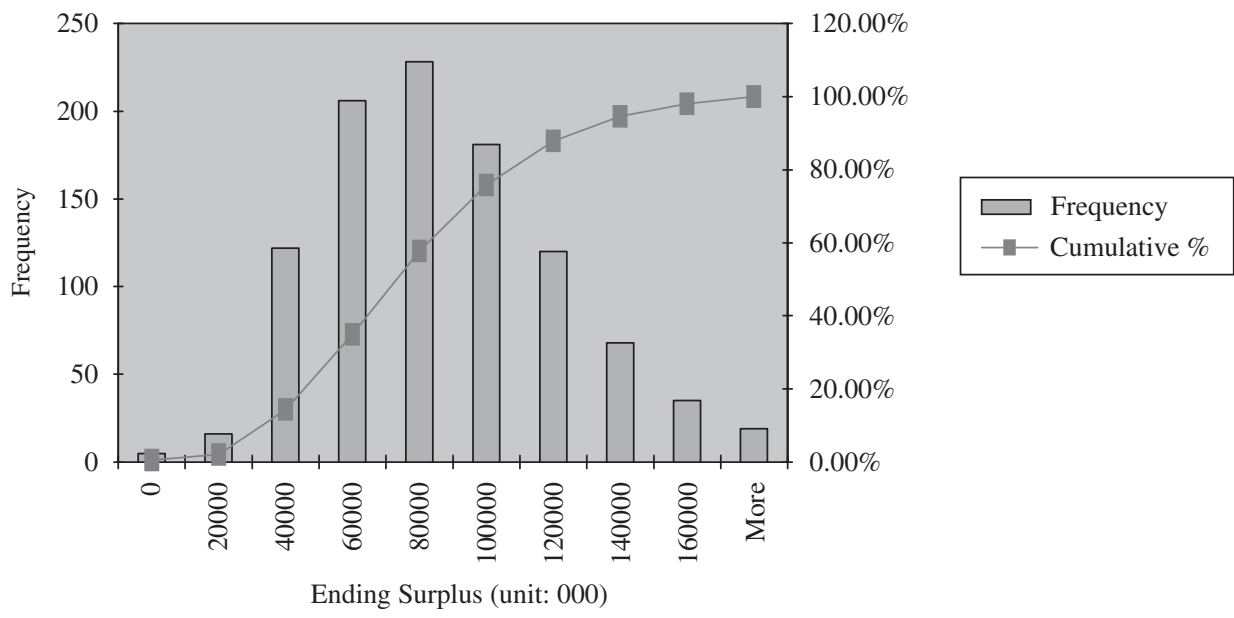

Figure 1. Distribution of ending surplus (FAAS 1).

company will become insolvent in the period concerned, possibly due in part to the short forecast period and the firm's financial soundness.

As indicated by Ryan, ${ }^{23}$ management is concerned not only about solvency, but also about the overall stability of the results. As such, it would be interesting to investigate the distributions of surplus in more detail. Two observations are obtained from the results. First, the distributions of the ending surplus of the fixed asset allocation strategies are very similar to those of their dynamic counterparts. Owing to the similarity between the fixed and the dynamic results, the following discussion will focus only on the fixed strategies for simplicity reasons. Second, for the five fixed strategies FAAS 1 through FAAS 5, the probabilities that the surplus will fall below the beginning statutory surplus ( $\$ 40$ million) over a 5-year period are 14.3 per cent, 13.4 per cent, 12.0 per cent, 10.4 per cent and 21.3 per cent, respectively. The lowest equity strategy (FAAS 5) is demonstrated to be much riskier than the highest equity strategy (FAAS 1). As shown in Figures 1-5, the simulated distributions of ending surplus and cumulative percentages of these strategies are fairly different. The above five figures again confirm that equity investments result in a distribution of ending surpluses with a higher mean and standard deviation. It is noted that the simulated ending surplus of FAAS 1 is relatively normally distributed, whereas that of FAAS 5 is highly skewed. In addition, in the particular case in question, it can be seen from Figure 5 that most of the simulated ending surpluses are relatively small, although the distribution has a relatively low variance.

Table 6 shows the trade-off ratios of these strategies. The trade-off ratio is defined as the percentage change in the performance (return) measure divided by the percentage change in the risk measure. All the trade-off ratios are positive, which reflects efficient portfolios. That is, return and risk change in the same direction.

${ }^{23}$ Ryan (1984). 

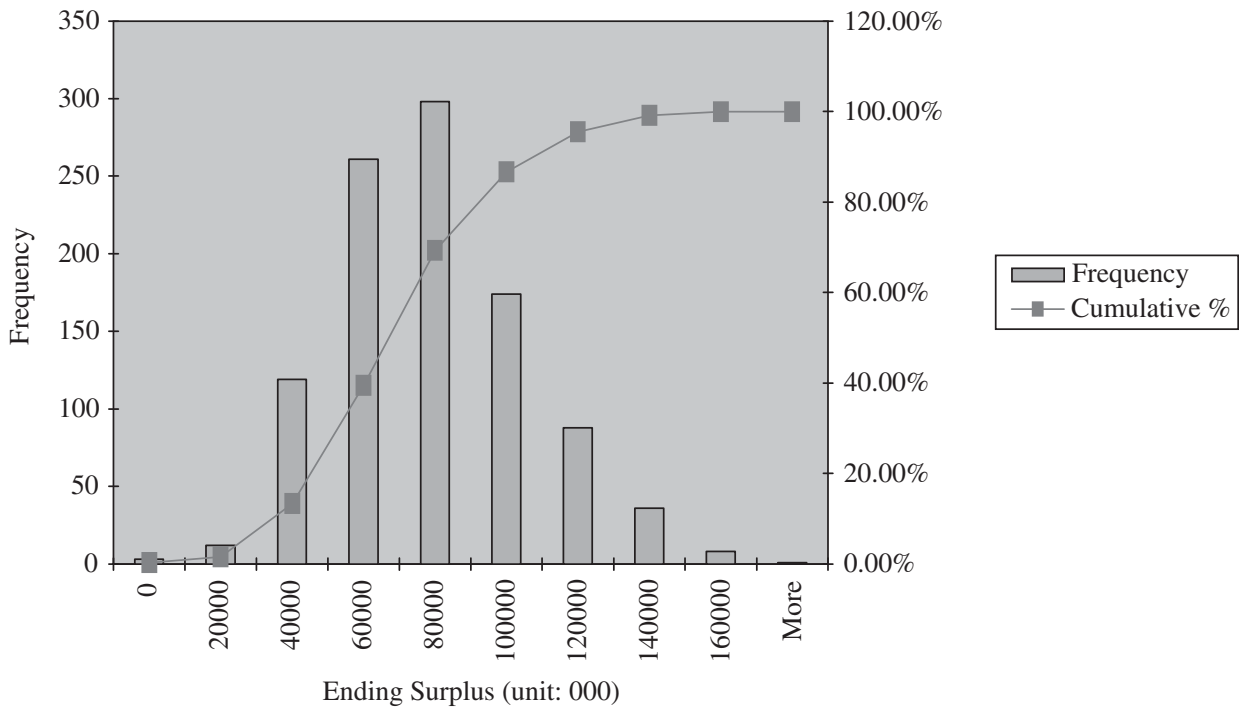

Figure 2. Distribution of ending surplus (FAAS 2).
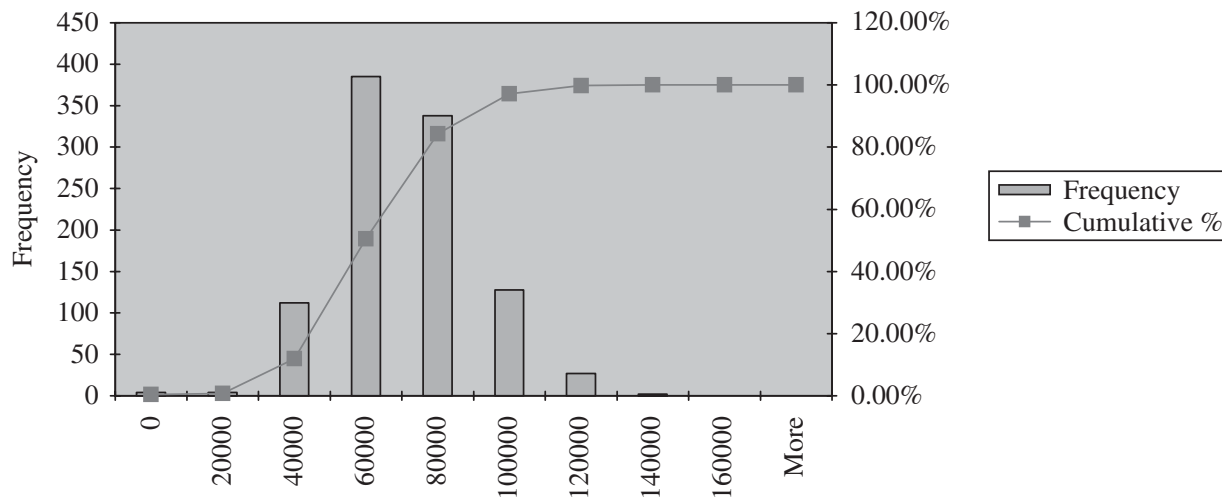

Ending Surplus (unit: 000)

Figure 3. Distribution of ending surplus (FAAS 3).

Figure 6 is a mean-standard deviation diagram for the five fixed asset allocation strategies. FAAS 1 with 100 per cent in equities has the highest risk and return, whereas FAAS 5 with 0 per cent has the lowest. This confirms that equity achieves much higher mean returns but with a much higher standard deviation of returns.

\section{Robustness testing}

Burkett et al. ${ }^{24}$ point out that sensitivity testing is required in a DFA exercise to ensure that the results obtained are robust and are not the product of a particular set

\footnotetext{
${ }^{24}$ Burkett et al. (2001).
} 

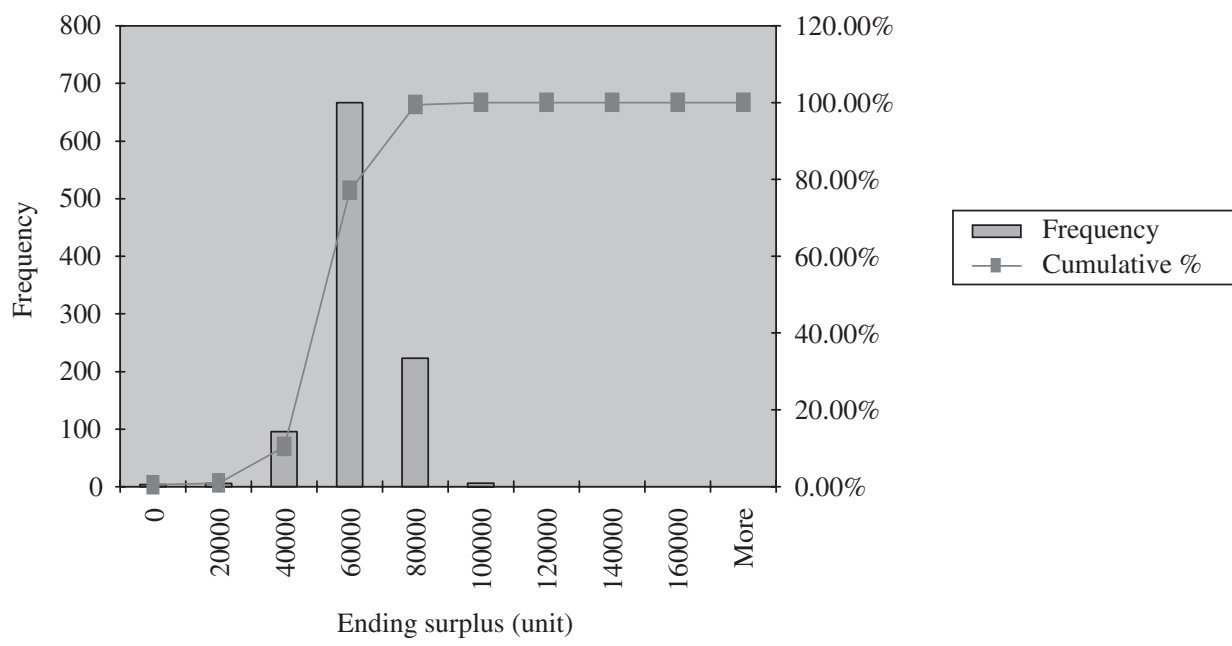

Figure 4. Distribution of ending surplus (FAAS 4).
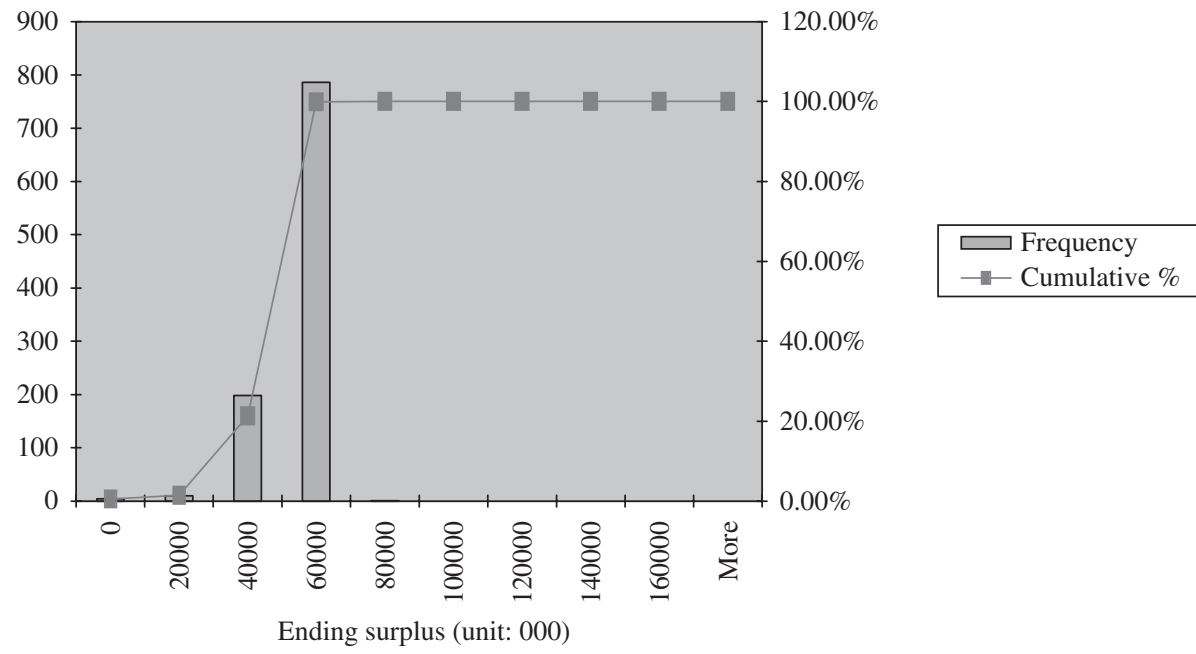

Figure 5. Distribution of ending surplus (FAAS 5).

of assumptions. By performing sensitivity analyses, the modeller can examine how the original results react to the changes in the initial assumptions. Specifically, sensitivity testing helps actuaries identify and evaluate key levers for management strategy decision making. ${ }^{25}$ Thus, with a view to testing the robustness of the results of the analysis, sensitivity tests of key input factors are carried out such as interest rates, new

${ }^{25}$ Sweeney et al. (1998). 
Table 6 Trade-off ratios of fixed asset allocation strategies

\begin{tabular}{lccl}
\hline & Mean Surplus & Standard deviation of surplus & \multicolumn{1}{c}{ Trade-off ratio(\%) } \\
\hline FAAS 1 & $76,918,000$ & $35,348,000$ & FAAS $_{1,2}=39.26$ \\
FAAS 2 & $69,020,000$ & $27,371,000$ & FAAS $_{2,3}=33.36$ \\
FAAS 3 & $60,814,000$ & $19,489,000$ & FAAS $_{3,4}=27.80$ \\
FAAS 4 & $52,329,000$ & $12,309,000$ & FAAS $_{4,5}=48.18$ \\
FAAS 5 & $43,578,000$ & $8,688,000$ & N/A \\
\hline
\end{tabular}

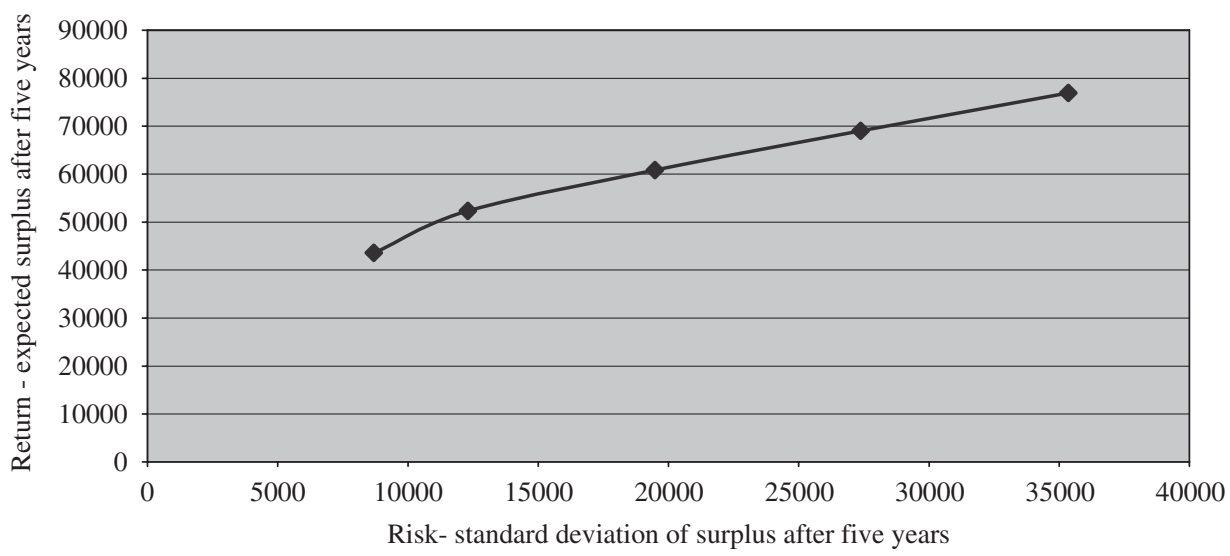

Figure 6. Risk-return trade off for five asset allocations (\$000).

exposure growth rates, renewal ratios and loss and expense ratios. As stated previously, sensitivity testing involves changing one variable at a time. However, there are too many key input factors that can be varied. For illustrative purposes, it was decided to vary the assumptions regarding the interest rate. The reason why interest rate was chosen is because it is the driving factor in the model. Both the long-term mean interest rate and the reversion parameter are varied to test whether their changes have a significant impact on ending surplus. Since the results of varying long-term mean interest rate and reversion parameter are similar, only the former is reported and discussed here.

The long-term mean interest rate in the base case is 6 per cent. Two alternative longterm mean interest rates ( 5 per cent and 7 per cent) are selected to assess their impact on ending surplus. Table 7 shows the mean, standard deviation, minimum, maximum and first and 99th percentile values from 1,000 simulations for each of the five fixed strategies. The sensitivities to the changes in the value for long-term mean interest rate are different. On average, every percentage point change in the long-term mean interest rate results in an increase in the ending surplus of $\$ 356,000, \$ 201,000$, $\$ 100,000, \$ 48,000$ and $\$ 44,000$ for strategies FAAS 1 through FAAS 5. The above changes in surplus only account for less than 1 per cent of the beginning surplus. This is shown graphically in Figure 7. These results suggest that the 
Table 7 Sensitivity test of long-term mean interest rate (unit: \$000)

\begin{tabular}{|c|c|c|c|c|c|c|}
\hline & Mean & S.D. & Minimum & Maximum & $1 \%$ & $99 \%$ \\
\hline \multicolumn{7}{|c|}{ Long-term mean interest rate $m=5 \%$} \\
\hline FAAS 1 & 76,571 & 35,026 & $-39,396$ & 198,551 & 12,495 & 166,420 \\
\hline FAAS 2 & 68,784 & 27,088 & $-48,898$ & 162,480 & 17,871 & 136,969 \\
\hline FAAS 3 & 60,667 & 19,234 & $-58,921$ & 125,388 & 22,351 & 106,980 \\
\hline FAAS 4 & 52,259 & 12,056 & $-69,292$ & 89,046 & 22,451 & 77,798 \\
\hline FAAS 5 & 43,573 & 8,434 & $-80,018$ & 61,109 & 16,974 & 54,706 \\
\hline \multicolumn{7}{|c|}{ Long-term mean interest rate $m=6 \%$ (Base case) } \\
\hline FAAS 1 & 76,918 & 35,348 & $-39,752$ & 200,656 & 11,286 & 167,580 \\
\hline FAAS 2 & 69,020 & 27,371 & $-49,422$ & 164,188 & 16,978 & 138,171 \\
\hline FAAS 3 & 60,814 & 19,489 & $-59,582$ & 126,701 & 22,159 & 107,954 \\
\hline FAAS 4 & 52,329 & 12,309 & $-70,073$ & 90,184 & 21,955 & 77,707 \\
\hline FAAS 5 & 43,578 & 8,688 & $-80,900$ & 60,101 & 15,627 & 54,916 \\
\hline \multicolumn{7}{|c|}{ Long-term mean interest rate $m=7 \%$} \\
\hline FAAS 1 & 77,283 & 35,660 & $-40,183$ & 202,819 & 10,711 & 169,127 \\
\hline FAAS 2 & 69,186 & 27,556 & $-50,175$ & 165,347 & 15,882 & 139,179 \\
\hline FAAS 3 & 60,866 & 19,627 & $-60,532$ & 127,199 & 20,745 & 108,411 \\
\hline FAAS 4 & 52,354 & 12,496 & $-71,104$ & 90,252 & 20,684 & 78,461 \\
\hline FAAS 5 & 43,660 & 8,931 & $-81,894$ & 60,724 & 14,412 & 54,987 \\
\hline
\end{tabular}

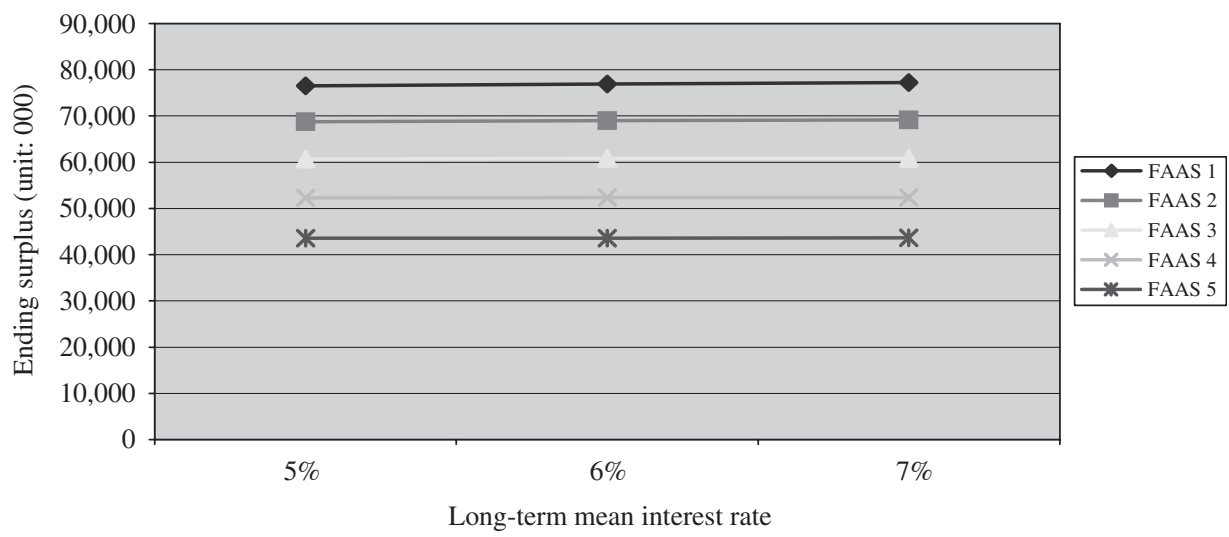

Figure 7. Ending surplus vs. long-term mean interest rate.

conclusions obtained in this paper are robust in terms of the sensitivity test of longterm mean interest rate.

In this section, DynaMo 3 is used to illustrate how a stochastic DFA model works in non-life business for the purposes of asset allocation and solvency testing. It is worth noting that the illustrative evaluation of asset allocation strategies is carried out in the context of all insurance operations, which include both underwriting and investment activities, unlike traditional asset allocation that only focuses on the investment side. 
Some conclusions from the results obtained can be summarised as follows. First, the dynamic asset allocation strategies considered appear to offer little advantage over the fixed asset allocation strategies in terms of the numbers of insolvencies. Second, equity investments achieve much higher mean returns than do bond investments, but also with a much higher standard deviation of returns. Third, the trade-off ratios of the fixed strategies are all positive, reflecting efficient portfolios. That is, return and risk change in the same direction. Fourth, it appears that the results are robust in terms of the sensitivity tests conducted.

\section{Conclusion}

How should DFA be used in the context of insurance? First of all, there should be a qualified actuary or other suitable expert within the insurance company or acting as a consultant. He or she should be able to develop a complete DFA model and exercise the necessary judgement when using the model according to the circumstances of the particular company under a variety of market conditions. In general such a model is used to conduct various "what-if" analyses such as testing of the solvency status and the evaluation of different management strategies. Based on the DFA results obtained, a report on the financial condition of the insurer should be prepared and presented to the Board. This report will be of particular interest not only to company management and those involved in developing business plans, but also to supervisory regulators.

The importance of conducting DFA/DST was confirmed by the interview organisations. However, the qualitative evidence obtained in the interviews shows that the organisations' capability of using DFA/DST-related techniques varied considerably and the ability of organisations to allow for interactions between assets and liabilities was in general restricted. All companies expressed a desire to work on or further develop their capability of stochastic modelling techniques in the near future. It is worth noting that it is also the policy of the FSA to encourage insurance companies to conduct stochastic modelling.

In this paper, a stochastic DFA model is used to show how it works in general for the purpose of asset allocation in the non-life sector. The invested assets are limited to equities and bonds. Ten asset allocation strategies including five fixed and five dynamic strategies are considered in the analysis. The five fixed asset allocation strategies range from 100 to 0 per cent in equities. The corresponding dynamic asset allocation strategies are determined by a dynamic asset-switching algorithm. Some conclusions from the results obtained can be summarised as follows: (1) the dynamic asset allocation strategies considered appear to offer little advantage over the fixed asset allocation strategies in terms of the numbers of insolvencies; (2) equity investments achieve much higher mean returns than do bond investments, but also with a much higher standard deviation of returns; (3) the trade-off ratios of the fixed strategies are all positive, reflecting efficient portfolios. That is, return and risk change in the same direction; and (4) it appears that the results are robust in terms of the sensitivity tests conducted.

This paper has provided evidence regarding the use of DFA/FCR in the U.K. insurance industry. Although DFA/FCR is still not widely practiced, evidence is clear 
that even those companies that have not fully employed DFA/FCR are taking a more integrated approach to developing DFA/FCR than in the past. In addition, a DFA model is applied to solvency testing and asset allocation.

The findings obtained from this paper have important implications for the insurance regulator and the actuarial profession. The first is that the FSA and the Faculty and Institute of Actuaries may consider introducing a Guidance Note on DFA/FCR specifically for non-life actuaries. Moreover, it would be desirable and welcomed by the profession for improving Guidance Notes to some extent. For instance, more guidance on stochastic modelling can be provided. Second, in addition to exercising professional judgement, actuaries may consider employing some statistical or econometric analysis to assist them in identifying the risk factors to be included in DFA modelling. Finally, in order to generate a more complete and accurate picture of the financial condition of an insurer, more emphasis on the interrelationships between balance sheet items should be placed while carrying out a DFA exercise.

However, this study inevitably has limitations. For instance, the generalisability of the findings obtained might be restricted because only five organisations have been interviewed. The small sample size also potentially limits the applicability of any statistical analysis. Limitations notwithstanding, the interview evidence provides important insight into the DFA/FCR practices in the U.K. insurance sector. Although at present there is little empirical research on the investigation of DFA/FCR practices and important risk factors in the context of insurance, adopting risk-based approaches to regulating insurance business by the supervisory authority will surely lead to an increase in the level of research activity in this field.

\section{References}

Bohra, R. and Weist, T. (2001) 'Preliminary due diligence of DFA insurance company', Casualty Actuarial Society Forum, (spring): 25-58.

Burkett, J.C., McIntyre, T.S. and Sonlin, S.M. (2001) 'DFA insurance company case study, part I: Reinsurance and asset allocation', Casualty Actuarial Society Forum, (spring): 59-98.

Chan, K.C., Karolyi, G.S., Longstaff, F.A. and Sanders, A.B. (1992) 'An empirical comparison of alternative models of the short-term interest rate', Journal of Finance 47: 1209-1227.

Christofides, S. (2000) 'Discussion of "Corporate decisions in general insurance: Beyond the frontier", by M. P. Cumberworth, A. N. Hitchcox, W. D. McConnel, and A. D. Smith', British Actuarial Journal 6: $259-296$.

D’Arcy, S.P., Gorvett, R.W., Herbers, J.A., Hettinger, T.E., Lehmann, S.G. and Miller, M.J. (1997) 'Building a public access PC-based DFA model', Casualty Actuarial Society Forum, (summer): 1-40.

D’Arcy, S.P., Gorvett, R.W., Hettinger, T.E. and Walling, R.J. (1998) 'Using the public access DFA model: A case study', Casualty Actuarial Society Forum, 53-118.

Dynamic Solvency Testing Working Party (1994) Dynamic Solvency Testing, The Proceedings of Current Issues in Life Assurance, Seminar, the Faculty and Institute of Actuaries. Staple Inn Hall, UK.

Eisenhardt, K.M. (1989) 'Building theories from case study research', Academy of Management Review 14(4): 532-550.

Gillham, B. (2000) Developing a Questionnaire, U.K.: Continuum.

Hardy, M.R. (1996) 'Simulating the relative solvency of life insurers', British Actuarial Journal 2(IV): 1003-1019.

Huber, P. (1995) 'A review of Wilkie's stochastic asset model', British Actuarial Journal 1: 181-211.

KPMG (1999) Proposal in relation to a scheme of arrangement between Sovereign Marine \& General Insurance Company Limited and its scheme creditors. 
Lowe, S.P. and Stanard, J.N. (1996) 'An integrated dynamic financial analysis and decision support system for a property catastrophe reinsurer', Casualty Actuarial Society Forum, (spring): 89-118.

Macdonald, A.S. (1995) A Stochastic Evaluation of Solvency Valuations for Life Offices, PhD Thesis, Heriot-Watt University, UK.

Macdonald, A.S. (1997) 'Current actuarial modelling practice and related issues and questions', North American Actuarial Journal 1(3): 24-37.

Muir, M. and Sarjant, S. (1997) Dynamic Solvency Testing, paper presented to the Staple Inn Actuarial Society, 4 March 1997.

Nowman, K.B. (1997) 'Gaussian estimation of single-factor continuous time models of the term structure of interest rates', Journal of Finance 5: 1695-1706.

Rubin, J. and Rubin, I. (1995) Qualitative Interviewing: The Art of Hearing Data, U.S.A.: Sage Publications.

Ryan, J.P. (1984) 'Application of simulation techniques to solvency testing for a non-life office', Transactions of the $22^{\text {nd }}$ International Congress of Actuaries 3: 269-277.

Shiu, Y. and Moles, P. (2006) 'Use of dynamic financial analysis and financial condition reporting by United Kingdom general Insurers', Annals of Actuarial Science 1: 79-101.

Shiu, Y., Moles, P., Adams, A. and Chan, C. (2006) 'Empirical evidence on the use of dynamic solvency testing and financial condition reporting in the United Kingdom life insurance industry', Annals of Actuarial Science 1: 359-392.

Strauss, A. and Corbin, J. (1990) Basics of Qualitative Research: Grounded Theory Procedures and Techniques, U.S.A.: Sage Publications.

Sweeney, J.C., Sonlin, S., Correnti, S. and Williams, A.P. (1998) 'Optimal insurance asset allocation in a multi-currency environment', in W. Ziemba and J. Mulvey (eds.) World Wide Asset and Liability Modelling, 1st edn, U.K.: Cambridge University Press.

Walling, R.J., Hettinger, T.E., Emma, C.C. and Ackerman, S. (1999) 'Customizing the public access model using publicly available data', Casualty Actuarial Society Forum, (summer): 239-266.

\section{About the Author}

Yung-Ming Shiu is Associate Professor in the Department of Business Administration at National Cheng Kung University, Taiwan. He teaches risk management and insurance. Dr. Shiu's research focuses on the areas of dynamic financial analysis, corporate hedging, risk management and insurance. His research has appeared in a number of scholarly and trade journals such as the Journal of Futures Markets, the Annals of Actuarial Science and the British Actuarial Journal. 